Ferraris AM, Mangerini R, Gaetani GF, Romei C, Pinchera A, Pacini F (1997) Polyclonal origin of medullary carcinoma of the thyroid in multiple endocrine neoplasia type 2 . Hum Genet 99:202-205

Forni GL, Melevendi C, Jappelli S, Rasore-Quartino A (1993) Dyskeratosis congenita: unusual presenting features within a kindred. Pediatr Hematol Oncol 10:145-149

Gealy WJ, Dwyer JM, Harley JB (1980) Allelic exclusion of glucose-6-phosphate dehydrogenase in platelets and T lymphocytes from a Wiskott-Aldrich syndrome carrier. Lancet 8159:63-65

Knight SW, Vulliamy T, Forni GL, Oscier D, Mason PJ, Dokal I (1996) Fine mapping of the dyskeratosis congenita locus in Xq28. J Med Genet 33:993-995

Langlois S, Junker A, Yong SL, Yam I, Livingston J, Siminovitch K (1993) Carrier females for X-linked dyskeratosis congenita show nonrandom $\mathrm{X}$ inactivation. Am J Hum Genet Suppl 51:1188

Marsh JC, Will AJ, Hows JM, Sartori P, Darbyshire PJ, Williamson PJ, Oscier DG, et al (1992) "Stem cell" origin of the hematopoietic defect in dyskeratosis congenita. Blood 79:3138-3144

Naumova AK, Plenge RM, Bird LM, Leppert M, Morgan K, Willard HF, Sapienza C (1996) Heritability of X chromosome-inactivation phenotype in a large family. Am J Hum Genet 58:1111-1119

Puck JM, Nussbaum RL, Conley ME (1987) Carrier detection in X-linked severe combined immunodeficiency based on patterns of $\mathrm{X}$ chromosome inactivation. J Clin Invest 79: 1395-1400

Willman, CL, Busque L, Griffith BB, Favara BE, McClain KL, Duncan MH, Gilliland DG (1994) Langerhans'-cell histiocytosis (histiocytosis $\mathrm{X}$ )-a clonal proliferative disease. $\mathrm{N}$ Engl J Med 331:154-160

Address for correspondence and reprints: Dr. Anna Maria Ferraris, Ematologia Oncologica, IST, Largo Rosanna Benzi, 10, 16132 Genova, Italy. (C) 1997 by The American Society of Human Genetics. All rights reserved. $0002-9297 / 97 / 6102-0028 \$ 02.00$

Am. J. Hum. Genet. 61:461-462, 1997

\section{Is There an Abnormal Phenotype Associated with Maternal Isodisomy for Chromosome 2 in the Presence of Two Isochromosomes?}

To the Editor:

We read with great interest the recent report by Bernasconi et al. (1996) describing a case of maternal isodisomy 2 due to the de novo inheritance of two isochromosomes for chromosome 2 . We recently identified an additional case of maternal isodisomy 2 also caused by the de novo inheritance of two isochromosomes for chromosome 2. However, in our case, the child has some significant features that are in common with recently reported cases of maternal disomy 2 (Bernard et al.

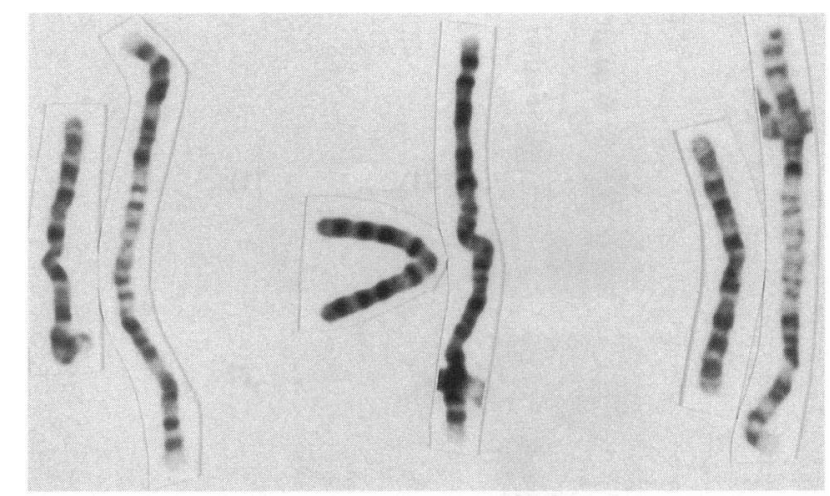

Figure 1 Three partial G-banded metaphases showing the isochromosome for $2 \mathrm{p}$ (left) and the isochromosome for $2 \mathrm{q}$ (right) in the proband.

1995; Harrison et al. 1995; Webb et al. 1996). Our case was the $785-\mathrm{g}$ male product of a 31-wk gestation to a 28-year-old G2P0 mother. Delivery was via cesarean section because of pregnancy-induced hypertension, severe intrauterine growth retardation (IUGR), and marked oligohydramnios. Apgar scores were 8 and 9 at 1 and $5 \mathrm{~min}$, respectively. The birth weight and length $(33 \mathrm{~cm})$ were significantly below the $3 \mathrm{~d}$ percentile $(10$ th percentile for 26-wk gestation). The baby was stable on room air until $13 \mathrm{~d}$ of age, when he had an acute deterioration, with low oxygen saturation requiring hood oxygen of $40 \%-80 \%$ for several days. His oxygen requirements dropped into the $23 \%$ range by $3 \mathrm{wk}$ of age, and he continued to require oxygen until 12 mo of age. At 2 mo of age a chest $x$-ray showed bilateral interstitial densities resembling bronchopulmonary dysplasia. At birth, a perineal hypospadias was evident and was subsequently repaired. Bilateral preauricular ear pits and significant pectus carinatum, without other dysmorphic features, were noted during an examination at 8 years of age. At this time, his height was $116 \mathrm{~cm}$ $(<2$ SD for age, corrected for midparental height). Chromosome analyses revealed an apparently nonmosaic 46,XY,i(2)(p10),i(2)(q10) karyotype (fig. 1). Molecular studies using seven dinucleotide-repeat polymorphisms for chromosome 2 revealed inheritance of only maternal alleles and failure of inheritance of any paternal alleles in the child (fig. 2). Additionally, the mother was heterozygous for all markers tested, and the child inherited only one allele for each marker, resulting in homozygosity for both chromosome arms, consistent with isochromosomes. The finding of true isochromosomes in our case and in that reported by Bernasconi et al. (1996) most likely formed through misdivision of the centromere in a monosomy- 2 conceptus. Other possibilities, as discussed elsewhere (Bernasconi et al. 1996), also exist.

In sharp contrast to the case presented by Bernasconi et al., in which there were no apparent phenotypic ab- 


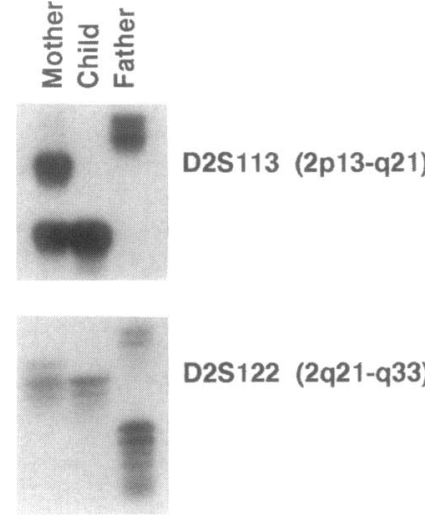

Figure 2 Molecular results for two markers located on $2 p$ (D2S113) and 2q (D2S122). The child shows the homozygous inheritance of a single maternal allele and failure to inherit a paternal allele.

normalities or unusual childhood illnesses, our patient and three previously reported patients with maternal disomy 2 had both severe IUGR with oligohydramnios or anhydramnios and postnatal growth retardation (Bernard et al. 1995; Harrison et al. 1995; Webb et al. 1996; present study), atypical bronchopulmonary dysplasia (Harrison et al. 1995; present study) or pulmonary hypoplasia (Bernard et al. 1995), hypospadias (current case; Bernard et al. 1995), and good motor and intellectual development (Harrison et al. 1995; Webb et al. 1996; present study). Our case also had preauricular ear pits, pectus carinatum, and fifth-finger clinodactyly. Of interest, perineal hypospadias has recently been reported in association with placental dysfunction and IUGR (Nesbitt et al. 1996). The possible causes for the phenotypic features associated with maternal disomy 2 include maternal imprinting effects of chromosome 2, unmasking of autosomal recessive disease due to homozygosity, undetected low-level fetal mosaicism for trisomy 2 , or placental dysfunction secondary to trisomy- 2 mosaicism or uniparental disomy (UPD). Two of the previously reported cases had demonstrated confined placental mosaicism for trisomy 2 (Bernard et al. 1995; Webb et al. 1996). The finding of no phenotypic abnormalities in the case reported by Bernasconi et al. (1996) is suggestive that the findings in these other four cases (Bernard et al. 1995; Harrison et al. 1995; Webb et al. 1996; present study) are not contributed by or influenced by the maternal UPD. However, the common features of IUGR, oligohydramnios/anhydramnios, pulmonary dysplasia/hypoplasia, and hypospadias suggest the possibility of an underlying etiology. Cases identified with placental mosaicism for trisomy 2 and/or maternal UPD 2 should be assessed prenatally for oligohydramnios and IUGR and postnatally for hypospadias, bronchopulmonary dysplasia, and growth retardation. Through identification and assessment of additional cases, the clinical impact of maternal disomy 2 and placental mosaicism for trisomy 2 can be delineated.

Lisa G. SHAFFER, ${ }^{1}$ CHRISTOPHER MCCASKILL, ${ }^{1}$ CATHERINE A. EGLI, JOHN C. BAKER,${ }^{2}$ AND KATHREEN M. JOHNSTON ${ }^{2}$

${ }^{1}$ Department of Molecular and Human Genetics, Baylor College of Medicine, Houston; Department of Pediatrics, Permanente Medical Group, ${ }^{2}$ San Francisco and ${ }^{3}$ Oakland

\section{References}

Bernard LE, Kalousek DK, Langlois S, Barrett IJ, Hansen WF, Aylsworth AS, Smith DI, et al (1995) Confined placental mosaicism for trisomy 2 with fetal maternal uniparental disomy of chromosome 2. Am J Hum Genet Suppl 57:A51

Bernasconi F, Karagüzel A, Celep F, Keser I, Lüleci G, Dutly F, Schinzel AA (1996) Normal phenotype with maternal isodisomy in a female with two isochromosomes: $\mathrm{i}(2 \mathrm{p})$ and i(2q). Am J Hum Genet 59:1114-1118

Harrison K, Eisenger K, Anyane-Yeboa K, Brown S (1995) Maternal uniparental disomy of chromosome 2 in a baby with trisomy 2 mosaicism in amniotic fluid culture. Am J Med Genet 58:147-151

Nesbitt TH, Bodine CL, Kahler SG, Decker-Phillips M (1996) Abnormal genital development in XY neonates associated with severe placental insufficiency and chronic intrauterine growth restriction. Am J Hum Genet Suppl 59:A40

Webb AL, Sturgiss S, Warwicker P, Robson SC, Goodship JA, Wolstenholme J (1996) Maternal uniparental disomy for chromosome 2 in association with confined placental mosaicism for trisomy 2 and severe intrauterine growth retardation. Prenat Diagn 16:958-962

Address for correspondence and reprints: Dr. Lisa G. Shaffer, Department of Molecular and Human Genetics, Baylor College of Medicine, One Baylor Plaza, Room 15E, Houston, TX 77030. E-mail: lshaffer@bcm.tmc.edu (C) 1997 by The American Society of Human Genetics. All rights reserved. 0002-9297/97/6102-0029\$02.00

Am. J. Hum. Genet. 61:462-466, 1997

\section{Evidence for a Possible Asian Origin of $\mathrm{YAP}^{+} \mathrm{Y}$ Chromosomes}

To the Editor:

The nonrecombining portion of the human Y chromosome has become an important tool for evolutionary studies (Hammer and Zegura, 1996). Its exclusive paternal inheritance and lack of recombination with the $\mathrm{X}$ chromosome preserve a unique record of mutational events from previous generations. Mutational changes that have occurred a single time in human evolution can be used to construct bifurcating haplotype trees that 